\title{
Impact of fine sediment discharge from paddy fields on river water quality: a case study focusing on the rice farming calendar
}

\author{
T. Ishikawa ${ }^{1} \&$ Y. Zhang $^{2}$ \\ ${ }^{I}$ Department of Civil and Environmental Engineering, \\ Hosei University, Japan \\ ${ }^{2}$ College of Plant Science, Jilin University, China
}

\begin{abstract}
The influence of fine sediment discharge from paddy fields on river water turbidity was investigated on the alluvial plain of the Eai River, Northeast Japan. The study comprises three phases: (1) Field measurements in a drainage channel from a rice paddy plot (3.7 ha); (2) Analysis of river turbidity data; (3) Discussion of the relationship between the two data sets. During data processing, turbidity was transformed to suspended solid (SS) flux for quantitative discussion, and particular attention was paid to the "farming calendar", which is a rice production manual prepared nationwide by farmers cooperatives. The data obtained in the drainage channel were analyzed using the Hayashi's quantification method II and the Galerkin method to derive an empirical equation for daily $S S$ flux from the paddy plot. The results clearly showed the dependency of SS flux on the stage of the farming calendar as well as the daily precipitation. Analysis of the available river turbidity data showed that $S S$ flux increased in the river reach where the paddy field discharge was concentrated; that the relationship between turbidity and $S S$ in the downstream river reach was consistent with the relationship from the solution of paddy field sediment measured in the laboratory; and that the river turbidity occasionally exceeded the critical level for fish adaptation during the mid-summer drying period of the farming calendar. Application of the empirical equation for $S S$ flux derived from the paddy plot measurements to the tributary watershed scale $(3,100 \mathrm{ha})$ successfully reproduced the order of turbidity variation during the irrigation period in the downstream river reach.
\end{abstract}

Keywords: SS discharge, paddy field, farming calendar, Feld measurements. 


\section{Introduction}

More than half of the agricultural area in Japan is occupied by paddy fields used to grow rice, which is a staple part of the Japanese diet. Rice production is mainly supported by river water irrigation [1] and, during the irrigation period, water rights for the paddy fields have priority over other water uses in cities and industries. The development of modern facilities for stable irrigation has reduced the dependency of rice production on direct rainfall to the paddy fields. As a result, excess water due to intensive rainfall is discharged into rivers, transporting fine sediment from the paddy surface, which increases the turbidity of the river water.

Additionally, a paddy operation is controlled by the "farming calendar", which is a rice production manual prepared by each farmers' cooperative affiliated with the Central Union of Agricultural Cooperatives. The calendar indicates the timing of the standard ponding and drainage processes corresponding to the type and growth stage of the rice crop. Therefore, the rate of fine sediment discharge may vary with each stage in the farming calendar.

Fig. 1 illustrates an example of the rice farming calendar [2], in which eight stages are considered: puddling and planting (1), deep ponding (2), shallow ponding $(3,6)$, mid-summer drying $(4)$, intermittent ponding $(5,7)$ and final drying (8). The objective and the operation of each stage are introduced in the relevant literature [3]. Several researchers have reported high turbid discharge during the puddling stage [4-6], which is the first stage in the calendar, when the soil surface is mixed and flattened before planting. However, sediment discharge during the other stages has not yet been investigated.

In this study, the influence of fine sediment discharge from paddy fields on river water turbidity was investigated during the entire irrigation period on the alluvial plain of the Eai River which is one of large rice-production areas in Northeast Japan. Data from continuous turbidity measurements in a drainage channel from a paddy plot $(3.7 \mathrm{ha})$ were analyzed using the Hayashi's quantification method II [7], taking the stages in the farming calendar and the rainfall intensity as the influential parameters. River turbidity data published by the River Administration Bureau were analyzed to determine the turbidity increase in the river reach where the paddy field discharge was concentrated, and the empirical equation for $S S$ flux derived from the paddy plot data set was applied to the tributary scale watershed (3,100 ha). In this paper, methods, results and discussions are described in the section for each research step to state the considerations in each study process clearly.

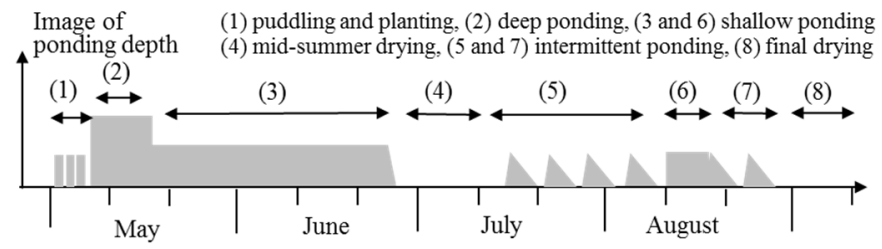

Figure 1: Example of the rice farming calendar [1]. 


\section{Study site}

The configuration and land cover of Eai River catchment are shown in Fig. 2, where the locations of intake barrages and water gauges are plotted as B-\# and G-\#, respectively. The source of the river is located in the central mountains of Northeast Japan, and from there it flows across the alluvial plain to join the Kitakami River flowing to the Pacific Ocean. The total catchment area of the Eai River is $577 \mathrm{~km}^{2}$, divided into upstream $\left(210 \mathrm{~km}^{2}\right)$ and downstream $\left(367 \mathrm{~km}^{2}\right)$ areas by Naruko Dam. More than $60 \%$ of the alluvial plain (downstream from B-1) is occupied by paddy fields.

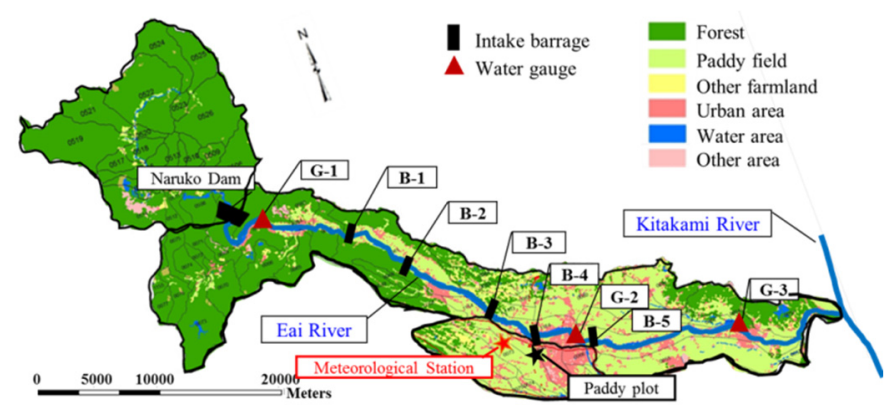

Figure 2: Eai River catchment highlighting land cover.

Fig. 3 illustrates the main irrigation and drainage channel network. The vertical black bars across the Eai River show the locations of the intake barrages, and the numbers below them indicate the corresponding irrigation areas (ha). The yellow arrows show the main drainage channels, and the numbers in boxes indicate the corresponding drainage areas (ha). Major drainage channels are connected to tributaries of the Eai River and the adjacent Naruse River. There are three water gauges (indicated by red triangles on the main channel), which continuously monitor the river discharge. Orange dots indicated on the main

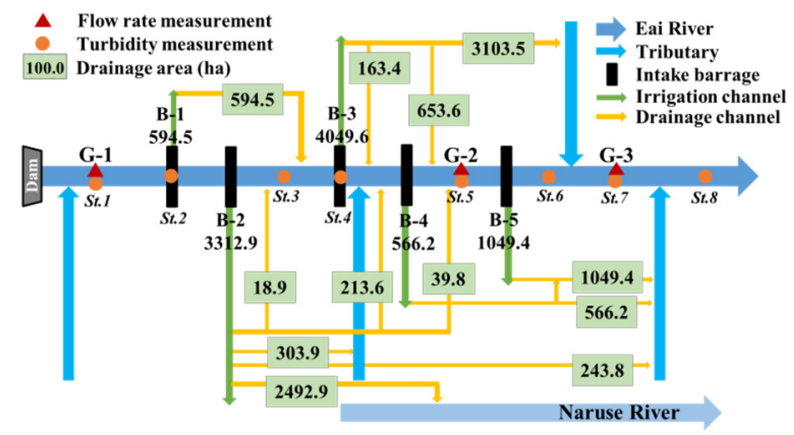

Figure 3: Illustration of the irrigation and drainage channel network. 
channel show the locations of the stations where river turbidity was measured. River discharge and turbidity data were published by the River Administration Bureau.

\section{Paddy plot field measurements}

Flow and turbidity were continuously measured in a drainage channel from a paddy plot (3.7 ha) to evaluate the flux of suspended solid $(S S)$ from the plot during the irrigation period of 2014 (April 27-August 31). The measurement site and the location of the nearest meteorological station are indicated with black and orange asterisks, respectively (in Fig. 2). Surface soil was sampled in the paddy field to analyze the grain size distribution and the correlation between turbidity and SS. The results of soil sample analysis are shown in Fig. 4. The sediment was characterized by silt-loam, with a mean grain diameter of $\sim 10 \mu \mathrm{m}$. The regression line in Fig. 4(b) was used to estimate $S S$ at each time interval.

Fig. 5 summarizes the measurement results. The black dots show the daily average $S S$ flux, the vertical blue bars show the daily precipitation recorded at the meteorological station, and the numbers in parentheses above the figure indicate the stages of the rice farming calendar that were illustrated in Fig. 1. Paddy operation during the year generally followed the standard calendar. The pink hatched area indicates an absence of measurements resulting from problems with equipment. Two large $S S$ peaks occurred in late April and late August,
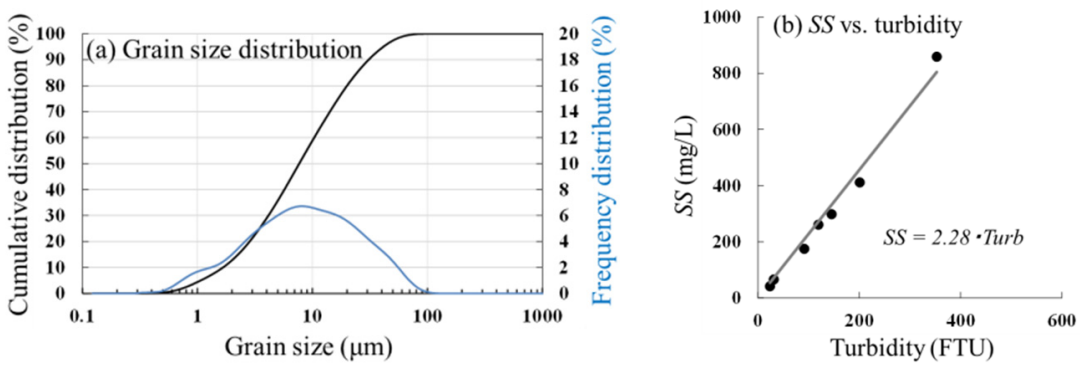

Figure 4: Characteristics of surface soil.

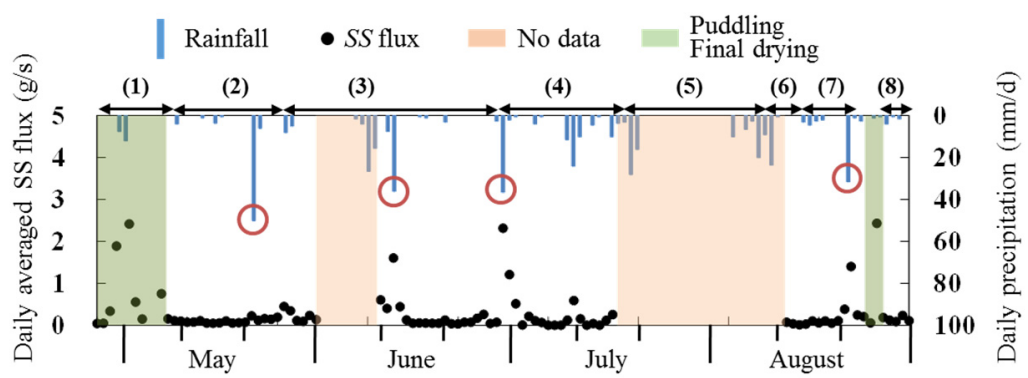

Figure 5: Measurement results. 
despite low daily precipitation, because of high discharge during puddling and final drying (highlighted by the green shaded areas in Fig. 5). The remaining $S S$ peaks correspond to the daily precipitation; however, the correlation between these two variables is not strong, for example, the four rainfall events indicated by red circles show very different $S S$ responses although the daily precipitation was similar.

\section{Paddy plot turbidity analysis}

\subsection{Hayashi's quantification method II [7]}

Table 1 shows the categories ( 1 and 2$)$ and items (a-e) defined for the analysis, with the number of samples for each items. The items in the paddy operation category correspond to the five stages of the farming calendar: deep ponding (2), shallow ponding (3 and 6), mid-summer drying (4), intermittent ponding (5 and 7 ), and final drying (8). Twenty four events with daily precipitation $>0.5 \mathrm{~mm}$ were analyzed. Five items were defined in the precipitation category with reference to the rain intensity classification proposed by the Japan Meteorological Agency [8]. The threshold value for separation of the SS flux data was determined to be $0.5 \mathrm{gr} / \mathrm{s}$ by several trials calculations to find the optimum value that would give the maximum standard deviation between the groups separated by the threshold [7].

Figure 6 shows the resultant item scores for each category. The average of the total scores for the 24 samples is zero for each category. Figure 6(a) shows that the $S S$ flux is relatively high during the mid-summer drying period (4), when the

Table 1: Categories and items for mathematical quantification analysis class-2.

\begin{tabular}{|l|l|c||c|c|c|}
\hline \multicolumn{3}{|c||}{ 1. Paddy operation $(T)$} & \multicolumn{3}{c|}{ Daily precipitation $(R)$} \\
\hline (a) & Deep ponding (2) & 4 & (a) & $0-3 \mathrm{~mm} / \mathrm{d}$ & 8 \\
\hline (b) & Shallow ponding (3, 6) & 4 & (b) & $3-10 \mathrm{~mm} / \mathrm{d}$ & 10 \\
\hline (c) & Mid-summer drying (4) & 7 & (c) & $10-20 \mathrm{~mm} / \mathrm{d}$ & 1 \\
\hline (d) & Intermittent ponding (5, 7) & 6 & (d) & $20-30 \mathrm{~mm} / \mathrm{d}$ & 1 \\
\hline (e) & Final drying (8) & 3 & (e) & $30-50 \mathrm{~mm} / \mathrm{d}$ & 4 \\
\hline
\end{tabular}
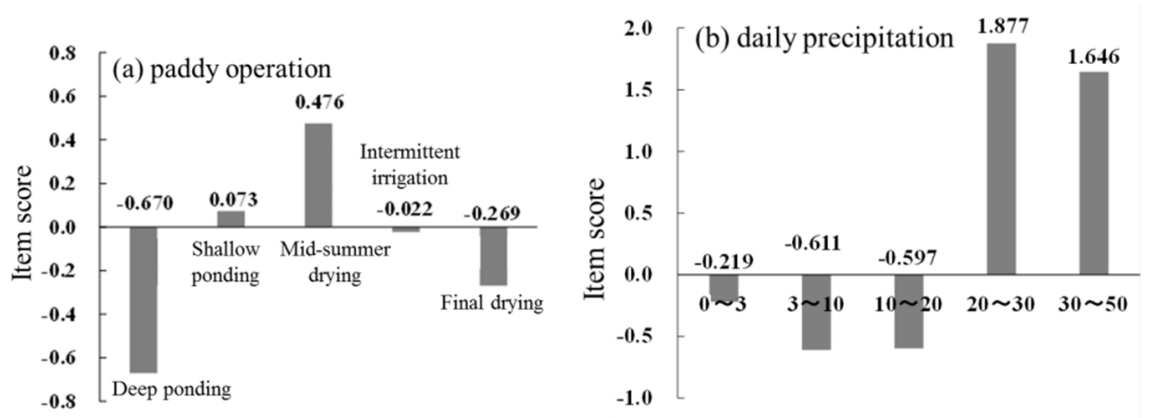

Figure 6: Item scores. (a) Paddy operation; (b) daily precipitation. 
ground is dry and the raindrops hit the soil, and relatively low during the deep ponding period (2), when the soil is submerged by deep water. The score of the final drying period (8) is also relatively low, even though the soil is not submerged by water. This result is likely to be due to interception of the rainfall by the crown of fully matured rice crops. Figure 6(b) shows a sharp increase in $S S$ flux when the daily precipitation exceeds $20 \mathrm{~mm}$.

\subsection{Empirical expression of $S S$ flux}

Based on the results from the above analysis, an empirical expression for $S S$ flux was derived using the Galerkin method as described below. The regression equation type was assumed as follows:

$$
F S S_{P}=a \cdot\left[f_{1}(T)+C_{1}\right] \cdot\left[f_{2}(R)+C_{2}\right]=a \cdot g_{1}(T) \cdot g_{2}(R)
$$

where $F S S_{P}$ is the daily average $S S$ flux recorded from the experimental paddy field (3.7 ha); $f_{1}(T)$ and $f_{2}(R)$ are the item scores for each category (paddy operation $T$ and daily rainfall $R$ ); and $a, C_{1}$, and $C_{2}$ are unknown constants.

The weighted residual method, which is the most common mathematical methods for approximation and regression analysis, assumes the orthogonality of the residual function $e(x)$ to some weighting function $w(x)$, where $x$ is an independent variable. It covers a variety of mathematical techniques, such as the least-squares method, the method of moments, the Galerkin method, etc., by changing the weighting function [9].

$$
\int\{e(x) \times w(x)\} d x=\int[\{Y(x)-Z(x)\} \times w(x)] d x \rightarrow 0
$$

In the above equation, $Z(x)$ is the original function to be approximated, which corresponds to the observed $F S S_{P}$ in this study, and $Y(x)$ is the approximation or regression function. The present case has two variables, $T$ and $R$, in eqn (1), therefore, the residual function is written as follows:

$$
\begin{aligned}
& e(T, R)=Y(T, R)-Z(T, R)=\alpha\left\{f_{1}(T)+C_{1}\right\} \cdot\left\{f_{2}(R)+C_{2}\right\}-Z(T, R) \\
& \quad=a \cdot f_{1}(T) \cdot f(R)_{2}+a \cdot C_{2} \cdot f(T)_{1}+a \cdot C_{1} \cdot f_{2}(R)+a \cdot C_{1} \cdot C_{2}-Z(T, R)
\end{aligned}
$$

The Galerkin method adopts the trial functions contained in the residual function for the weighting functions [9], which are $f_{1}(\mathrm{~T}), f_{2}(\mathrm{R})$ and $f_{1}(\mathrm{~T}) \cdot f_{2}(\mathrm{R})$ in eqn (3). In the case of discrete data, the integral is replaced by the summation, and the Galerkin equation is written as follows:

$$
\begin{array}{r}
\sum_{j=1}^{N}\left[\left\{\left(a \cdot f_{1}\left(T_{j}\right) \cdot f_{2}\left(R_{j}\right)+a \cdot C_{2} \cdot f_{1}\left(T_{j}\right)+a \cdot C_{1} \cdot f_{2}\left(R_{j}\right)\right.\right.\right. \\
\left.\left.+a \cdot C_{1} \cdot C_{2}-Z\left(T_{j}, R_{j}\right)\right\} \cdot w_{i}(j)\right]=0
\end{array}
$$

where $N$ is the total number of data $(N=24)$, and $i$ is the number of weighting functions $(i=1 \sim 3)$, which are written respectively as follows:

$$
w_{1}(j)=f_{1}\left(T_{j}\right), \quad w_{2}(j)=f_{2}\left(R_{j}\right), \quad w_{3}(j)=f_{1}\left(T_{j}\right) \cdot f_{2}\left(R_{j}\right)
$$

Solving the three Galerkin equations $(i=1 \sim 3)$ simultaneously, the three unknown constants were determined as $a=0.32, C_{1}=1.37$ and $C_{2}=1.21$. Figure 7 
shows the results of the analyses: the red line in the latter is a combination of logistic curves to express the effect of precipitation continuously:

$$
g_{2}(R)=\left[\begin{array}{ll}
0.734 /\left\{1+10^{0.33(3.0-R)}\right\} & \text { for } R \leq 10 \mathrm{~mm} / \mathrm{d} \\
0.734+2.353 /\left\{1+10^{0.20(20.0-R)}\right\} & \text { for } R \geq 10 \mathrm{~mm} / \mathrm{d}
\end{array}\right.
$$
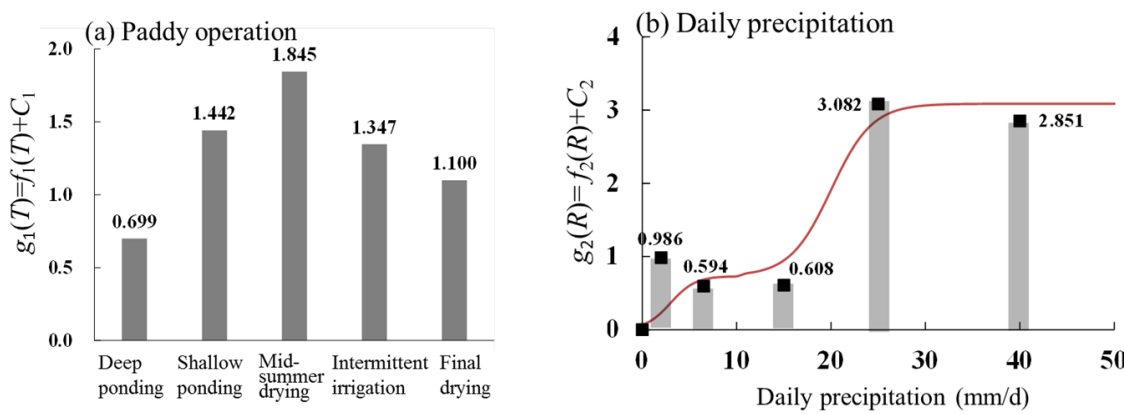

Figure 7: $\quad$ Result of analyses for $g_{1}(T)$ and $g_{2}(R)$ in eqn (1).

The red line in Fig. 8 shows the result of the simulation that was carried out for the irrigation period of 2014, which did not include the periods of mechanical drainage highlighted by the green shaded areas. There was a lack of data in the period indicated by pink shaded areas due to the problems with equipment mentioned earlier.

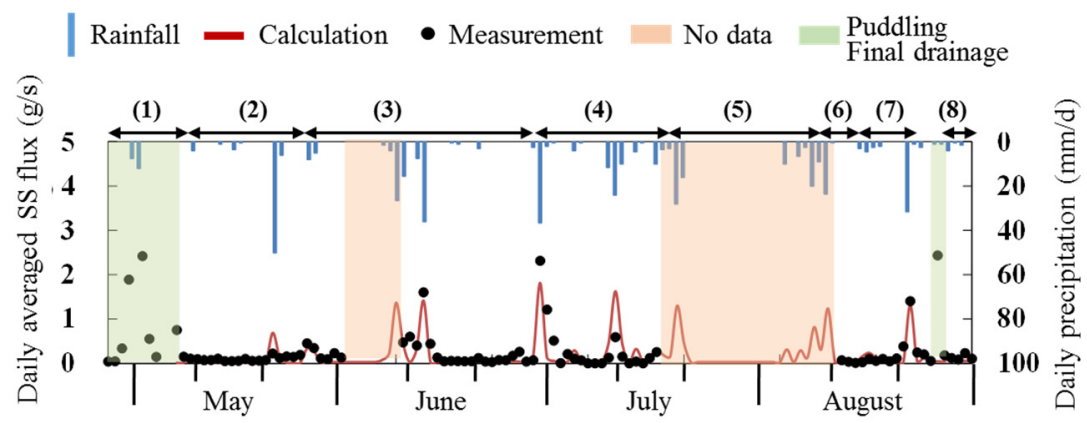

Figure 8: Result of simulation with observed data.

\section{River turbidity analysis}

\subsection{Data}

River turbidity was periodically measured by the River Administration Bureau at the eight locations shown in Fig. 3 during the irrigation periods of five years from 2010 to 2014. Fig. 9 shows the measurement dates; turbidity measurements were taken approximately every week from July to September with exception of 
2013 when measurements began at the end of May. The open and filled circles indicate the dates when precipitation was greater and less than $0.5 \mathrm{~mm} / \mathrm{d}$, respectively. The sampling frequency during earlier irrigation periods was lower because the government budget for local river administration offices was not available in the early part of the fiscal year, which began in April.

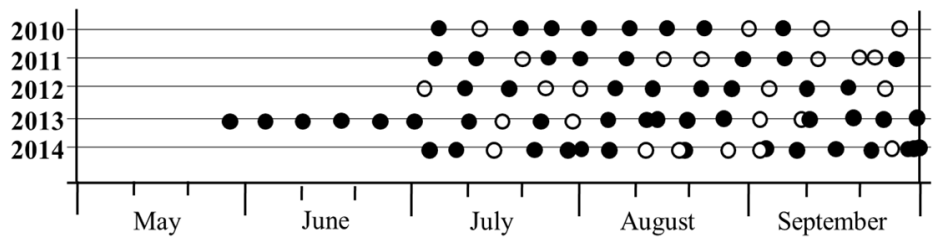

Figure 9: Dates of water sampling.

Fig. 10 shows the longitudinal variation in river turbidity averaged over the whole irrigation period (black) and the mid-summer drying only (blue). It shows a clear increase in turbidity in the reach downstream of St. 6, where the paddy field discharge concentrates (as shown in Fig. 3). The turbidity increment between St. 6 and St. 7 exceeded 10 FTU during the mid-summer drying period. Turbidity of this level may affect the dietary action of Plecoglossus altivelis, which is highly prized food fish species in Japan [10].

River water was sampled to analyze the correlation of $S S$ with turbidity. Fig. 11 shows the correlation results for two groups of measurement stations. The samples collected at the upstream stations (blue; St. 1-St. 4) and those at the

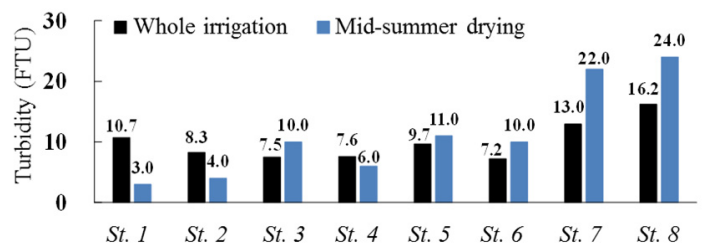

Figure 10: Longitudinal distribution of river turbidity.

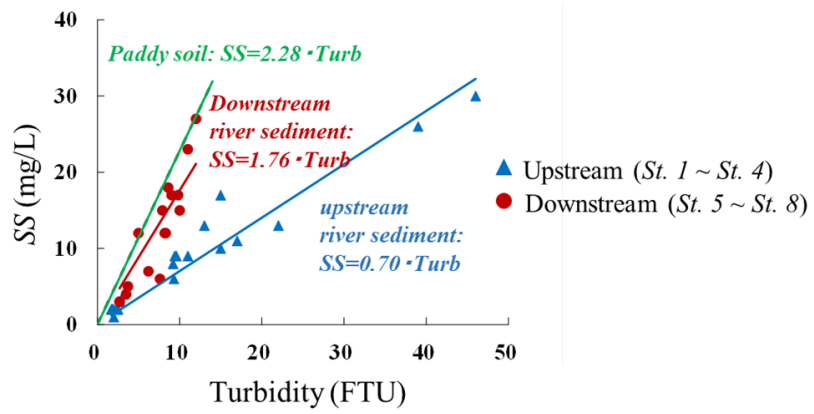

Figure 11: Correlation of SS with turbidity. 
downstream stations (red; St. 5-St. 8) show significantly different trend. The green line shows the correlation for the paddy soil from Fig. 4(b). The trend line for the downstream data closely matches that of the paddy soil data. This suggests that the water flow in the downstream river reach contains a much greater quantity of fine sediment discharged from the paddy field.

\subsection{Increment of SS flux between St. 6 and St. 7}

We analyzed the Increment of SS flux between St. 6 and St. 7, where the discharge from paddy field was most highly concentrated (Fig. 3). The measured turbidity was converted to $S S$ using the regression equation (red line in Fig. 11), and the $S S$ flux was calculated using the following equation.

$$
\Delta F S S=S S_{7} \cdot Q_{G 3}-S S_{6} \cdot\left(Q_{G 2}-Q_{B 5}\right)
$$

where $\triangle F S S$ is the $S S$ flux increment between the two stations; $S S_{6}$ and $S S_{7}$ are the $S S$ at $S t$. 6 and $S t$. 7, respectively: $Q_{\mathrm{G} 2}$ and $Q_{\mathrm{G} 3}$ are the river discharge at the two water gauge stations G-2 and G-3, respectively; and $Q_{\mathrm{B} 5}$ is the intake volume at barrage B-5 (Fig. 3).

The Hayashi's quantification method II was again adopted to compare the tendency of $S S$ flux increase in the river with the discharge from the paddy field. Table 2 shows the number of samples corresponding to the categories and items defined in the previous analysis (Table 1). There are no river water sample corresponding to items 1(a), 1(b) and 2(d).

Fig. 12 shows the resultant item scores for each category. The tendency of the score distributions is similar to the results for the paddy field discharge (Fig. 6);

Table 2: Categories and items for mathematical quantification analysis class- 2 .

\begin{tabular}{|c|c|c|c|c|c|}
\hline \multicolumn{3}{|c|}{ 1. $\quad$ Paddy operation } & \multicolumn{3}{|c|}{ Daily precipitation } \\
\hline (a) & Deep ponding (2) & 0 & (a) & $0-3 \mathrm{~mm} / \mathrm{d}$ & 13 \\
\hline (b) & Shallow ponding $(3,6)$ & 0 & (b) & $3-10 \mathrm{~mm} / \mathrm{d}$ & 5 \\
\hline (c) & Mid-summer drying (4) & 3 & (c) & $10-20 \mathrm{~mm} / \mathrm{d}$ & 4 \\
\hline (d) & Intermittent ponding $(5,7)$ & 9 & (d) & $20-30 \mathrm{~mm} / \mathrm{d}$ & 0 \\
\hline (e) & Final drying (8) & 13 & (e) & $30-50 \mathrm{~mm} / \mathrm{d}$ & 3 \\
\hline
\end{tabular}
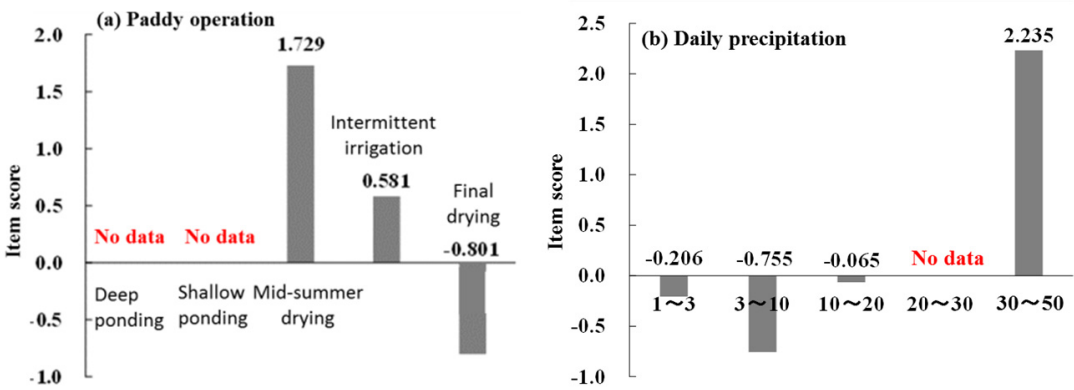

Figure 12: Item scores. (a) Paddy operation; (b) daily precipitation. 
showing [mid-summer drying $>$ intermittent irrigation $>$ final drying] in the paddy operation category, and the sharp increase between 20 and $30 \mathrm{~mm} / \mathrm{d}$ in the precipitation category. This similarity suggests that the $S S$ flux increase between the two stations was strongly influenced by the sediment discharge from the paddy field.

\subsection{Comparison of SS flux in the river and from the paddy field}

The drainage area of the river reach between St. 6 and St. 7 covers 3,100 ha as shown in Fig. 3. However, due to recent government policy taking account of the increase of bread as a Japanese staple food, as well as the necessity of constant rice import to provide food security in low harvest years, about $1 / 3$ of the paddy field area was out of cultivation. Therefore, the paddy field area in operation was assumed to be 2,055 ha, and the sediment discharge was calculated as follows:

$$
F S S_{C i}=F S S_{P} \frac{A_{P}}{A_{C}}
$$

where $F S S_{P}$ is the $S S$ flux from the experimental paddy plot, obtained from eqn. (1); $F S S_{C i}$ is the $S S$ flux from the target drainage area; and $A_{P}$ and $A_{C}$ are the corresponding areas (3.7 ha and 2,055 ha).

The drainage channel network between the paddy field and the river is extensive; therefore, the sediment flux may be altered by erosion and deposition along the wetted perimeter. This is illustrated in Fig. 13, in which $F S S_{C i}$ and $F S S_{C o}$ are the flux into and out of the drainage channel, respectively; $F S S_{6}$ and $\mathrm{FSS}_{7}$ are the flux in the upstream and downstream sections of the river reach, respectively; and $\triangle F S S$ is the increment of river sediment flux.

The sediment flux change in the drainage channel can be estimated using a number of sedimentary hydraulics formulae for a simple channel shape; however, it is not easy to estimate practically due to the complexity of channel networks and the lack of information regarding the geometry of the wetted perimeter. In addition, the volume of erosion and deposition in the river channel is not certain. Nevertheless, the data presented in Figs 10, 11 and 12 suggest that the sediment yield from the paddy field is a major factor contributing to the turbidity increase between the two stations. Therefore, the flux into the drainage channel, $F S S_{C i}$, is directly compared with the sediment flux increase, $\triangle F S S$.

Fig. 14 compares $F S S_{C i}$ from eqn. (8) with $\triangle F S S$ from eq. (7) over the five year periods from 2010 to 2014. The farming calendar for 2010-2013 was assumed to be the same as that of 2014. Daily precipitation was similarly

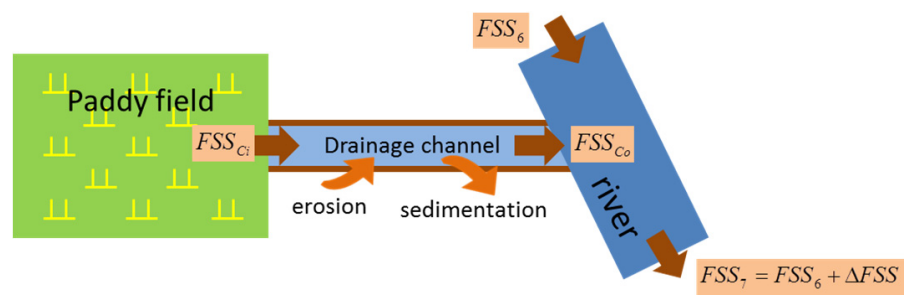

Figure 13: Flow of sediment flux. 

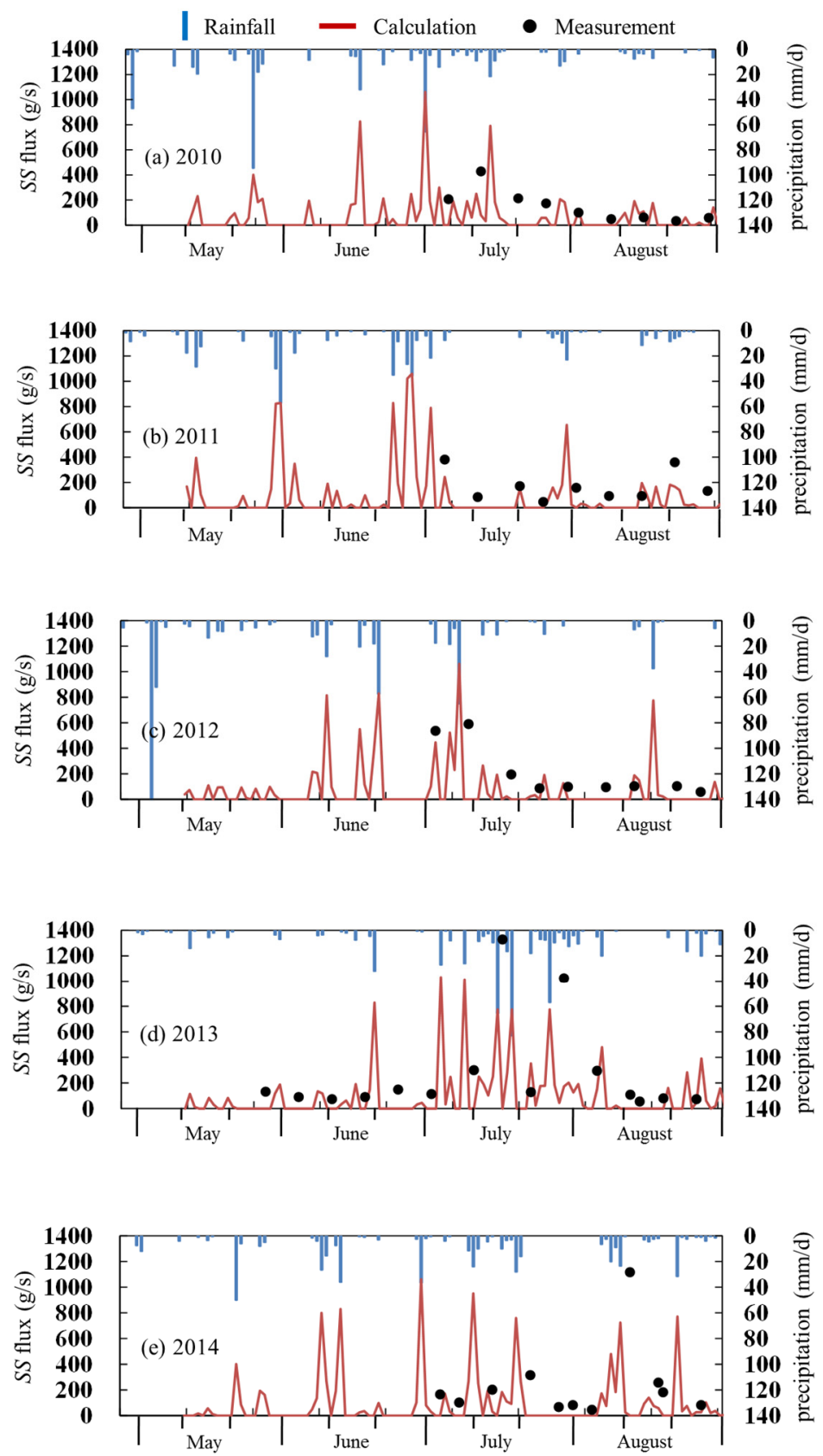

Figure 14: Comparison of the simulation and the observation (river SS flux increment between St. 6 and St. 7). 
obtained at the nearest meteorological station. The order of $S S$ flux and the overall tendency are reproduced fairly well; however, the time series agreement is less clear, possibly due to lack of modelling of the sediment processes in the drainage channel.

\section{Conclusion}

Field measurements of fine sediment discharge were carried out for a paddy plot covering an area of $3.7 \mathrm{ha}$, and the data were processed focusing on the rice production farming calendar. The results showed that sediment discharge largely depended on the stages of the farming calendar; discharge was relatively high during the mid-summer drying period and low during the deep ponding period. This suggests that paddy operation should be considered in hydrological modeling of paddy field areas during the irrigation period.

Spatial summation of $S S$ flux using the empirical relation obtained from the experimental data accounted for the order and overall tendency of turbidity increase in the river reach where the 3,100 ha paddy drainage area was concentrated. However, the results also showed that modeling of drainage channel sediment processes will be necessary for a more accurate evaluation of paddy field influence on river water quality.

\section{References}

[1] Japanese Institute of Irrigation \& Drainage: Characteristics and recent problems of irrigation in Japan, p. 54, 2003.

[2] Furukawa Agricultural Cooperative: JA Furukawa rice-cultivation calendar, 2014.

[3] Tabuchi, T. \& Hasegawa, S.: Paddy fields in the world, Japanese Society of Irrigation, Drainage and Reclamation Engineering, Japan, pp. 103-134, 1995.

[4] Wakai, T., Kaneki, R., Itakura, Y. \& Banno, M.: Water quality and loads of rivers during puddling transplanting period, J. Japan Soc. Hydrol. \& Water Resour., 18(2), pp. 167-176, 2005.

[5] Sudo, M., Miki, T. \& Masuda, Y.: Research on characteristics of turbid water effluent from paddy fields during the paddling and the transplanting period, Trans. of JSIDRE, 260, pp. 7-13, 2009.

[6] Somura, H., Takeda, I. \& Mori, Y.: Influence of puddling procedures on the quality of rice paddy drainage water, Agricultural Water Management, 96, pp. 1052-1058, 2009.

[7] Hayashi, C.: Multidimensional Quantification. II, Proceedings of Japan Academy, 30(3), pp. 165-169, 1954.

[8] Japan Meteorological Agency: Term of rainfall intensity, www.jma.go.jp /jma/kishou/know/yougo hp/kousui.html

[9] Finlayson, B. A.: The Method of Weighted Residuals and Variational Principles, Academic Press, New York, pp. 7-12, 1976.

[10] Central Research Institute of Electric Power Industry: Research Report of Effect on Freshwater Fish, 1981. 